\title{
Assessment of Vitamin D status in general population of Muzaffarabad district \& effect of supplementation on serum Vitamin D levels in general population of Muzaffarabad district.
}

\author{
Waqar Haider ${ }^{1}$, Ambreen Zaib ${ }^{1}$,Atif Abbasi ${ }^{2}$,Azhar Saleem ${ }^{2}$,Saadia Mir ${ }^{3}$ \\ Bakht Ramin Shah ${ }^{3}$, Nazneen Habib ${ }^{4}$,Javadan Haider ${ }^{5}$ \\ Sheikh Khalifa Bin Zeyad Al Nahyan Hospital CMH Muzaffarabad ${ }^{l}$ \\ Department of Statistics University of Azad Jammu \& Kashmir Muzaffarabad ${ }^{2}$ \\ Sheikh Khalifa Bin Zeyad Al Nahyan Hospital CMH Muzaffarabad ${ }^{3}$ \\ Department of Sociology University of Azad Jammu \& Kashmir Muzaffarabad ${ }^{4}$
}

\begin{abstract}
The status of vitamin D was assessed in the general population of the Muzaffarabad district having established coronary artery disease and other medical complaints. Results of the study showed that there is a deficiency or insufficiency of the vitamin in all the subjects enrolled for the study irrespective of their age, gender, occupation, socioeconomic conditions, daily sun exposure, supplementation history, body mass index and medical complaints. In the light of the findings that vitamin D is deficient or insufficient in $99 \%$ of the population and level is improved after administrating vitamin D as injection Sunny D. So it is suggested that the vitamin D supplementation may be added to the preventive program as a part of primary health care.
\end{abstract}

Key words: Vitamin D, Cornary artery disease,sunexposure, Muzaffarabad,Anova.

\section{Introduction}

Vitamin D, also known as 'the Sun Vitamin' is a steroid with hormone-like activity. It regulates the functions of over 200 genes and is essential for growth and development of the body (Masood et al, 2008). The two main sources of vitamin D are food and sunlight(Binkley et al, 2007). Generally natural food sources have low vitamin D content and therefore require fortification. Insufficient dietary supplies of vitamin D in countries where food stuffs are not fortified, leads to generally low dietary intake of vitamin D and calcium (Calvo et al, 2007).

Vitamin D deficiency is widespread throughout the world. It has been estimated that almost one billion people in the world suffer from vitamin D deficiency or insufficiency (Holick, 2007). The high prevalence of low vitamin D status is assumed to result from inadequate sun exposure. Because highly sunexposed individuals are supposed to possess normal vitamin D status (Rucker et al, 2002). However some individuals with seemingly adequate sun exposure have been reported to have low vitamin D levels (Binkley et al, 2007). Vitamin D deficiency is quite prevalent throughout the world, but it appears to be the worst in the countries of South Asia, especially among children, women and elderly. Poor diet, cultural practices of the region and poverty are some of the important reasons for vitamin D deficiency (Masood et al, 2008).

High prevalence of vitamin D deficiency in Asia can be due to skin pigmentation and traditional clothing. Air pollution and limited outdoor activity further compounds this problem in the urban population (Rashid et al, 1983). Vitamin D deficiency is considered to be responsible for rickets, birth defects, osteoporosis, osteoarthritis, osteomalacia, chronic pain and muscle pain (Masood et al, 2008).

Vitamin D is important for normal bone health (lips, 2001). For decades, adequate circulating Vitamin $\mathrm{D}(25 \mathrm{OHD})$ concentration is considered essential for maintenance of bone health while inadequate levels of $25 \mathrm{OHD}$ have classically been associated with bone disorders (Iqbal et al, 2010).. Vitamin D deficiency is a wellknown cause of rickets in children and osteomalacia in adults, and it is also of importance for development of osteoporosis. Beyond this, vitamin D deficiency is suggested as a contributing factor in the development of several other diseases and conditions such as cardiovascular diseases, diabetes, some types of cancer and immunologic diseases, neurological disorders and depression (Horlick, 2005).

In spite of the fact that this is mountainous area where people have relatively more rough and tough living habits, the incidence and prevalence of coronary artery disease (CAD) is quite high. This increased incidence is significant because many people have $\mathrm{CAD}$ even in the absence of established risk factors like smoking, diabetes, hypertension, and dyslipedemias. Another remarkable observation is that even people with normal Body mass index and having professions like brick masons, manual labourers, carpenters and other trades of this nature also have CAD with no established risk factors. The question remains that are we not getting enough sun exposure or are we breaking down this vitamin more rapidly? More detailed studies are required to unravel the cause of the vitamin D deficiency or insufficiency. In this study we have planned to 
assess the status of vitamin D in general population of Muzaffarabad District having different medical complaints and established coronary artery disease, and to point out the different causes and risk factors associated with it.

\section{Objectives:}

The specific objectives of the study were to;

- Assess Vitamin D status in general population of Muzaffarabad district.

- Assess vitamin D status in patients with established coronary artery disease.

- Assess Vitamin D levels in comparison with BMI, socioeconomic status, history of taking supplements and daily sun exposure in general population of Muzaffarabad district.

- Assess the improvement in the levels of Vitamin D after supplementation with Injection vitamin D3 (Injection Sunny D) in general population of Muzaffarabad district.

\section{Location of the study:}

\section{Methodology:}

A study related to determination of status of vitamin D in people of Muzaffarabad was carried out at Sheikh Khalifa Bin Zeyad Al Nehyan Combined Military Hospital Muzaffarabad Azad Kashmir from $1^{\text {st }}$ of October 2011 to $31^{\text {st }}$ January 2012.

\section{Sample size and selection of subjects:}

A total of four hundred and fifty individuals with age ranged 5-65 years were selected for the study. The inclusion criterion was to select individuals from General OPD and Cardiac OPD/ indoor patients. From general OPD/indoor patients we selected 400 people who came there with different complaints like acute infections, asthma, generalized body aches, hypertension and diabetes. While from cardiac OPD/indoor patients we selected 50 individuals who came with established coronary artery disease with or without the associated risk factors. After taking written consent a questionnaire regarding age, weight, height, BMI, gender, occupation, monthly income, duration of sun exposure, supplementation history and medical history was filled from all the subjects.

After filling the questionnaire all the individuals who were selected from general OPD/indoor patients were asked to take vitamin D supplementation for one month i.e. five injections of Sunny D orally. After one month 100 individuals were selected randomly from them for post supplementation assessment. While the 50 patients with established coronary artery disease were asked to take supplements regularly and were kept under observation for any further cardiovascular event.

\section{Blood collection \& sample analysis:}

Blood sample $(3 \mathrm{ml})$ was collected from all individuals in hospital using the standard procedure for blood collection. First blood sample was collected before giving vitamin D supplements and the second was collected after one month of vitamin D supplementation. Blood samples were sent to Excel Laboratory through Sajjadia Labs Muzaffarabad. There blood was analysed for vitamin D3 using Chemiluminescent Immune Assay (CLIA) method on Liaison.

\section{Anthropometry:}

Weight and height of all individuals were assessed by following the recommended procedure of WHO (1983). For taking weight and height measurements, a beam scale was calibrated with standard weights and measuring tapes. Before taking weight measurements, the volunteers were asked to remove heavy clothing, shoes, purse and other unnecessary things. The weight was noted up to the nearest $0.01 \mathrm{~kg}$. Similarly before height measurements, the subjects were asked to remove head cap, shoes and heavy garments and to stand in the centre of the platform of the scale, looking straight with his head, back, buttocks, calves and heels touching the rod. The head piece was leveled and height was recorded up to the nearest $0.1 \mathrm{~cm}$. Body mass index (BMI) was calculated prior to the experiment with the help of the following formula,

$$
\text { (Weight }(\mathrm{kg}) / \text { Height } \mathrm{m}^{2} \text {. }
$$

\section{Results and Discussion}

The collected data were entered into SPSS (statistical package for social sciences). One way ANOVA (Analysis of variance) was used to check the variation among the different groups at $5 \%$ level of significance. 
Table no. 1

\begin{tabular}{|l|l|c|c|}
\hline & \multicolumn{3}{|c|}{ Status of Vitamin D in males on the Basis of BMI Classification } \\
\cline { 1 - 2 } BMI classification & Mean \pm S.D & F-Value & P Value \\
\hline$<18.50$ & $24.133 \pm 16.51$ & & \multirow{2}{*}{30.006} \\
\cline { 1 - 2 } $18.5-24.9$ & $18.191 \pm 7.49$ & & \\
\cline { 1 - 2 } $25-29.99$ & $16.038 \pm 6.75$ & & \\
\hline$\geq 30$ & $19.300 \pm 19.67$ & & \\
\hline
\end{tabular}

Table no. 2

\begin{tabular}{|l|l|l|l|}
\hline & \multicolumn{3}{|c|}{ Status of vitamin D among males of different age groups } \\
\hline Age groups (years) & Mean \pm S.D & F-Value & P value \\
\hline $5-20$ & $16.638 \pm 6.75$ & & \multirow{2}{*}{20.46} \\
\cline { 1 - 2 } $21-35$ & $17.49 \pm 6.61$ & & \\
\cline { 1 - 2 } $36-50$ & $12.938 \pm 5.35$ & & \\
\cline { 1 - 2 } $51-65$ & $24.525 \pm 14.54$ & & \\
\hline
\end{tabular}

Table no. 3

\begin{tabular}{|l|l|c|c|}
\hline & \multicolumn{3}{|c|}{ Status of vitamin D Irrespective of the Gender } \\
\cline { 1 - 2 } Age groups (years) & Mean \pm S.D & F-Value & \multirow{2}{*}{ P value } \\
\hline $5-20$ & $14.776 \pm 8.78$ & \multirow{2}{*}{0.023} \\
\cline { 1 - 2 } $21-35$ & $14.952 \pm 8.11$ & & \\
\hline $36-50$ & $14.7 \pm 8.25$ & & \\
\hline $51-65$ & $19.172 \pm 12.89$ & & \\
\hline
\end{tabular}

Table.4

\begin{tabular}{|l|l|l|c|}
\hline & \multicolumn{3}{|c|}{ Status of Vitamin D on the Basis of BMI Classification irrespective of gender } \\
\hline BMI classification & Mean \pm S.D & F-Value & P Value \\
\hline$<18.50$ & $14.289 \pm 11.51$ & & \multirow{2}{*}{23.39} \\
\cline { 1 - 2 }-24.9 & $16.732 \pm 8.83$ & & \\
\hline $25-29.99$ & $14.388 \pm 7.82$ & & \\
\hline$\geq 30$ & $18.2 \pm 14.87$ & & \\
\hline
\end{tabular}

Table no. 5

\begin{tabular}{|l|l|l|l|}
\hline \multicolumn{3}{|c|}{ Status of vitamin D among females of different age groups } \\
\cline { 1 - 2 } Age groups(years) & Mean \pm S.D & F-Value & P value \\
\cline { 1 - 2 } $5-20$ & $12.758 \pm 10.48$ & \multirow{2}{*}{33.62} & \multirow{2}{*}{0.006} \\
\cline { 1 - 2 } $21-35$ & $13.26 \pm 8.77$ & & \\
\cline { 1 - 2 } $56-50$ & $16.608 \pm 10.47$ & & \\
\cline { 1 - 2 }-65 & $14.321 \pm 9.13$ & & \\
\hline
\end{tabular}

Table no.6

\begin{tabular}{|l|l|l|c|}
\hline \multicolumn{3}{|c|}{ Status of Vitamin D in females on the Basis of BMI Classification } \\
\hline BMI classification & Mean \pm S.D & F-Value & P Value \\
\hline$<18.50$ & $9.367 \pm 3.96$ & & \multirow{2}{*}{0.003} \\
\cline { 1 - 2 } $18.5-24.9$ & $15.273 \pm 9.96$ & & \\
\hline $25-29.99$ & $12.738 \pm 8.72$ & & \\
\hline
\end{tabular}


Table no. 7

\begin{tabular}{|l|l|c|c|}
\hline & \multicolumn{3}{|c|}{ Status of Vitamin D On the basis of daily Sun exposure } \\
\hline & Mean \pm S.D & F-Value & P Value \\
\hline positive sun exposure & $15.892 \pm 10.15$ & 36.67 & 0.009 \\
\hline negative sun exposure & $15.901 \pm 9.75$ & & \\
\hline
\end{tabular}

Table no. 8

\begin{tabular}{|l|l|c|c|}
\hline & \multicolumn{3}{|c|}{ Status of Vitamin D On the basis of history of taking supplements } \\
\hline & Mean \pm S.D & F-Value & P Value \\
\hline positive hx of supp & $15.724 \pm 10.16$ & 45.49 & 0.007 \\
\hline negative hx of supp & $16.310 \pm 8.86$ & & \\
\hline
\end{tabular}

Table no. 9

\begin{tabular}{|l|c|c|c|}
\hline & \multicolumn{3}{|c|}{ Status of Vitamin D On the basis of socio economic status } \\
\hline & Mean \pm S.D & F-Value & P Value \\
\hline Lower SES & $15.124 \pm 7.21$ & 40.6 & 0.004 \\
\hline Higher SES & $16.708 \pm 11.85$ & 4 \\
\hline
\end{tabular}

A total of 450 subjects participated in this study. Four hundred subjects (192 male and 208 female) from general OPD/indoor patients were included in this study (group I) while 50 were with established coronary artery disease (group II). The subjects in the group I were divided into 4 groups on the basis of age. The mean serum vitamin D for group I (5-20years) was $14.77 \mathrm{ng} / \mathrm{dl}$, for group II (21-35 yrs) was $14.95 \mathrm{ng} / \mathrm{dl}$, for group III (36-50 yrs) was $14.7 \mathrm{ng} / \mathrm{dl}$ and for group IV (51-65 yrs) was $19.17 \mathrm{ng} / \mathrm{dl}$. Similarly the subjects were divided into 4 groups on the basis of BMI. The mean serum vitamin D for group I (BMI<18.5) was $14.28 \mathrm{ng} / \mathrm{dl}$, for group II (18.5-24.9) was $16.73 \mathrm{ng} / \mathrm{dl}$, for group III (25-29.9) was $14.39 \mathrm{ng} / \mathrm{dl}$ and for group IV (BMI $\geq 30)$ was $18.2 \mathrm{ng} / \mathrm{dl}$. The subjects were also divided into different groups on the basis of daily sun exposure, supplementation and socioeconomic status. On the basis of daily sun exposure the subjects were divided into two groups, the mean vitamin D for those having daily sun exposure was $15.89 \mathrm{ng} / \mathrm{dl}$ and for those who do not have daily sun exposure was $15.90 \mathrm{ng} / \mathrm{dl}$. On the basis of taking supplements again subjects were divided into two groups, those who had taken supplements in past had mean serum vitamin D $15.72 \mathrm{ng} / \mathrm{dl}$ and those who had not taken supplements in past had vitamin D level at $16.31 \mathrm{ng} / \mathrm{dl}$. Similarly on the basis of socioeconomic status subjects were divided into two groups, the mean serum vitamin D for Group I (LSES) was $15.12 \mathrm{ng} / \mathrm{dl}$ and for group II (HSES) was $16.71 \mathrm{ng} / \mathrm{dl}$. The mean serum vitamin D for the patients of group II having established coronary artery disease was $15.5 \mathrm{ng} / \mathrm{dl}$.

In the second step we randomly selected 100 individuals who had taken vitamin D supplements to check whether there is any increase in their serum Vitamin D levels or not. The results showed that there was a change in serum vitamin D levels of the individuals who had taken one month supplementation of the vitamin. The minimum increase in the level of the vitamin was $21.1 \mathrm{ng} / \mathrm{dl}$ while the maximum increase was $59.5 \mathrm{ng} / \mathrm{dl}$.

\section{Discussion:}

Vitamin D plays a vital role in human body and its deficiency/insufficiency results in a number of disorders and diseases. It is of utmost importance to keep the vitamin D in the body at a desirable level for regular functioning of the body.

The result of the study shows that there is deficiency or insufficiency of vitamin D in general population of the Muzaffarabad district irrespective of age, gender, occupation, socioeconomic conditions, daily sun exposure, supplementation history and body mass index. In group II in which we have 50 patients with established coronary artery disease, they also have deficiency of the vitamin and level of vitamin D was below the sufficient level. We have found in results that administrating vitamin D as injection Sunny D has improved the level of vitamin D within the normal range.

\section{Conclusion and recommendations:}

Results of the study show that there is a deficiency or insufficiency of the vitamin D in general population of Muzaffarabad district irrespective of age, gender, socio-economic status, sun exposure, supplementation history and medical history. And there is a positive increase in the level of vitamin D after taking the supplement of vitamin D3 injections. However it is highly recommended to take the Vitamin D3 
supplements on a regular basis to overcome its deficiency or insufficiency and it should be added to the preventive program as a part of primary health care.

\section{References:}

[1]. Holick, M.F(2007). Vitamin D deficiency. N. Engl. J .Med; 357:266-81.

[2]. Masood, S.H., Iqbal, M.P(2008). Prevalence of vitamin D deficiency in South Asia. Pak. J .Med. Sci. 24(6): 891-97.

[3]. Iqbal, R., Aysha, H.K (2010). Possible Causes of Vitamin D Deficiency (VDD) in Pakistani Population Residing in Pakistan. J. Pak. Med. Assoc. 60(1): 1-2.

[4]. Calvo, M.S., Whiting, S.J., Barton, C.N (2007). Vitamin D Intake: A Global perspective of current status. J. Nutr; 135 : 310 -7.

[5]. Rucker, D., Allan, J.A., Fick, G.H., Hanley, D.A( 2002). Vitamin D insufficiency in population of healthy western Canadians. Can. Med. Assoc. J. 166:1517-1524.

[6]. Rashid. A., Mohammed, T., Stephens, W.P (1983). Vitamin D state of Asians living in Pakistan. Br. Med. J. $286: 182-184$.

[7]. Lips, P (2001). Vitamin D deficiency and secondary hyperparathyroidism in the elderly: consequences for bone loss and fractures and therapeutic implications. Endocr. Rev. 22: 477-501.

[8]. Holick, M.F (2005). Vitamin D: important for prevention of osteoporosis, cardiovascular heart disease, type 1 diabetes, autoimmune diseases, and some cancers. South. Med. J. 98: 1024-7.

[9]. $\quad$ Binkley, N., Novotny, R., Krueger, D., Kawahara,T., Daida, Y. G., Lensmeyer, G., Hollis, B. W., Drezner, M. K (2007). Low vitamin D status despite abundant sun exposure. J. Clin.l Endo. Metab. 92(6): 2130-2135. 